\title{
VERTEBRAL ARTERY INSUFFICIENCY IN ACUTE CERVICAL SPINE TRAUMA
}

\author{
By J. Trevor Hughes, M.D., M.R.C.P.E., D.C.P., D.Path. \\ The Radcliffe Infirmary, Oxford
}

ThE neurological damage caused by injuries to the cervical spine is variable in amount and may not correspond to the apparent severity of the bony injury. Of particular interest and puzzlement are those cases where radiological examination shows no fracture or displacement yet substantial spinal-cord damage has occurred. In cases such as those described in the papers of Barnes (1948), Taylor and Blackwood (1948), Symonds (1953), Schneider, Cherry and Pantek (1954) and Hughes and Brownell (1963), the mechanism is a hyperextension injury to the cervical spine of an elderly person with spondylosis. In these cases the spinal cord, tightly fitting into a spinal canal narrowed by cervical spondylosis, is squeezed by further narrowing caused by hyperextension of the neck. The forward movement of the ligamentum flavum during neck extension may be in these cases an important factor, Blackwood (1963). In contradistinction to the cases in which the spinal cord is directly crushed are other cases which do not fall into this category and the present paper deals with a small group in which the myelopathy is caused by injury to the vertebral arteries. Such traumatic involvement of the vertebral arteries was described by Schneider, Thompson and Bebin (1958), and in their paper is the first case report with this mechanism of the spinal cord lesion demonstrated at necropsy. The present paper records two cases in which a detailed necropsy demonstrated spinal cord ischaemia caused by an injury to the cervical spine affecting the vertebral arteries.

Case I. A 52-year-old factory worker was knocked down by a car whilst crossing the road. He sustained multiple injuries including scalp lacerations, a compound fracture of the left humerus, a fracture of the right clavicle and a large haematoma of the left thigh. Signs of intra-abdominal bleeding became apparent and at laparotomy a ruptured spleen was removed. His neurological examination on admission had been limited by confusion and oligaemic shock, but no localising neurological signs had been found. Twelve hours after his admission, following splenectomy and adequate blood transfusion, his general condition had improved and permitted a full neurological examination. He now had evidence of a cord lesion affecting segments C8 and TI asymmetrically giving a BrownSéquard type of picture, there being bilateral sensory and lower motor neurone loss at C8 and TI with a right hemiparesis and left hemi-hypesthesia and hypalgesia. A left Horner's syndrome was also present. X-rays of the cervical spine showed no fracture or displacement. He subsequently developed a respiratory infection and died on the fourth day after his accident.

Necropsy. The general necropsy findings outside the skeletal and nervous systems were myocardial ischaemic fibrosis and early bilateral bronchopneumonia.

Cervical Spine. The prevertebral muscles were infiltrated with haematoma and covered by a thin film of blood clot. Removal of this blood clot showed a gross tear through the $\mathrm{C}_{5-6}$ intervertebral disc (fig. I). This tear ran roughly transversely but with a wavy contour corresponding to the upper surface of C6 vertebral 


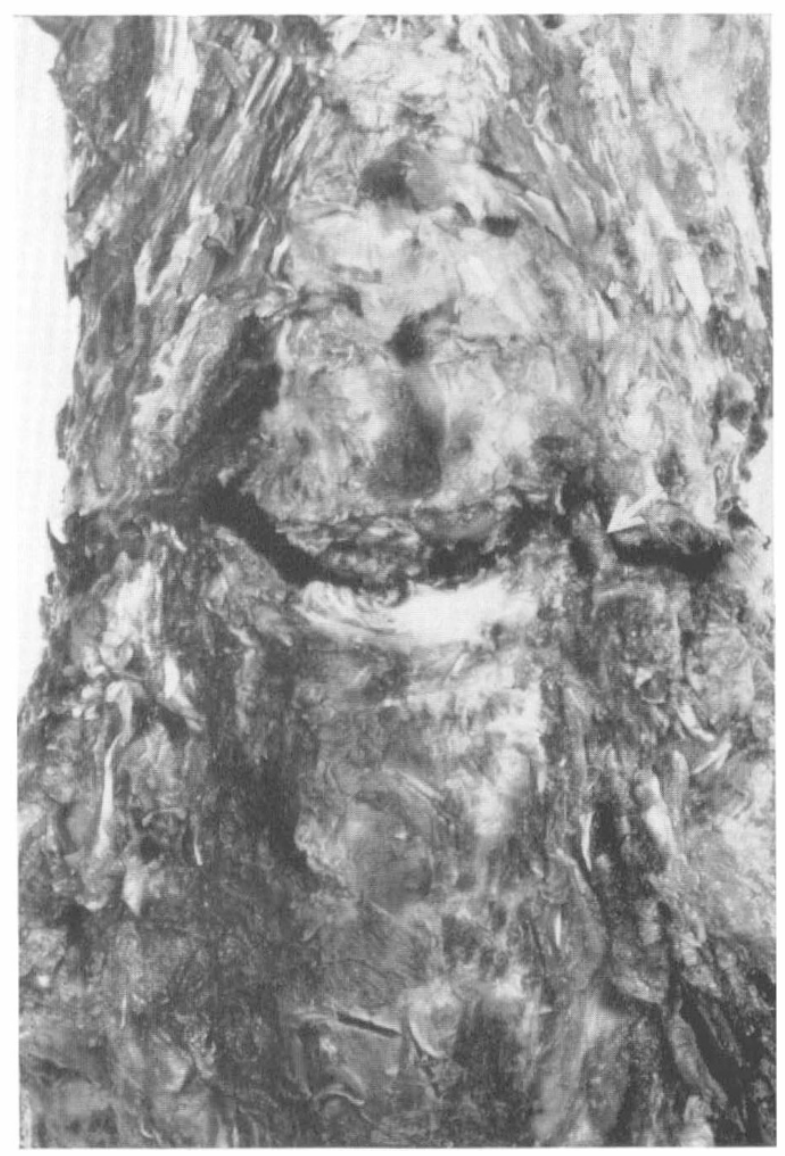

FIG I

Photograph showing the anterior aspect of the cervical spine in Case I. The C5-6 intervertebral disc is torn and the left vertebral artery (arrowed) is embedded in blood clot.

body. The anterior longitudinal (prevertebral) ligament was also torn as were the capsular ligaments of the $\mathrm{C}_{5}-6$ intervertebral joints. Both these joints were loose and the facets could be moved on one another but no fractures were associated with the joint subluxation. Consequent on the disc and capsular ligament tears the spine was abnormally hinged at $\mathrm{C}_{5}-6$, where the upper portion was permitted to angle backwards.

Spinal Canal. The spinal canal was examined from the posterior aspect by removal of the laminae. No haematoma was present within the canal, which showed no gross deformity when the spine was kept straight. If the upper portion was pressed backwards, angulation occurred up to 40 degrees backwards from the normal anatomical position. The abnormal angulation hinged on the posterior longitudinal ligament which was intact. 
Vertebral Arteries. After a little dissection both vertebral arteries could be seen as they passed through the region of the intervertebral disc tear (fig. I). Both were markedly kinked when angulation of the spine occurred. In addition to this the left vertebral artery was partially torn with some old blood clot surrounding the tear as a nodule $0.3 \mathrm{~cm}$. in diameter. The patency of each vertebral artery was investigated by fluid injection. The injection (by syringe) was made into the commencement of the vertebral artery and the outflow observed at its termination. With the cervical spine in the normal anatomical position the vertebral flow was normal but even slight hyperextension (and abnormal hinging due to the disc tear) caused obstruction of the flow of fluid.
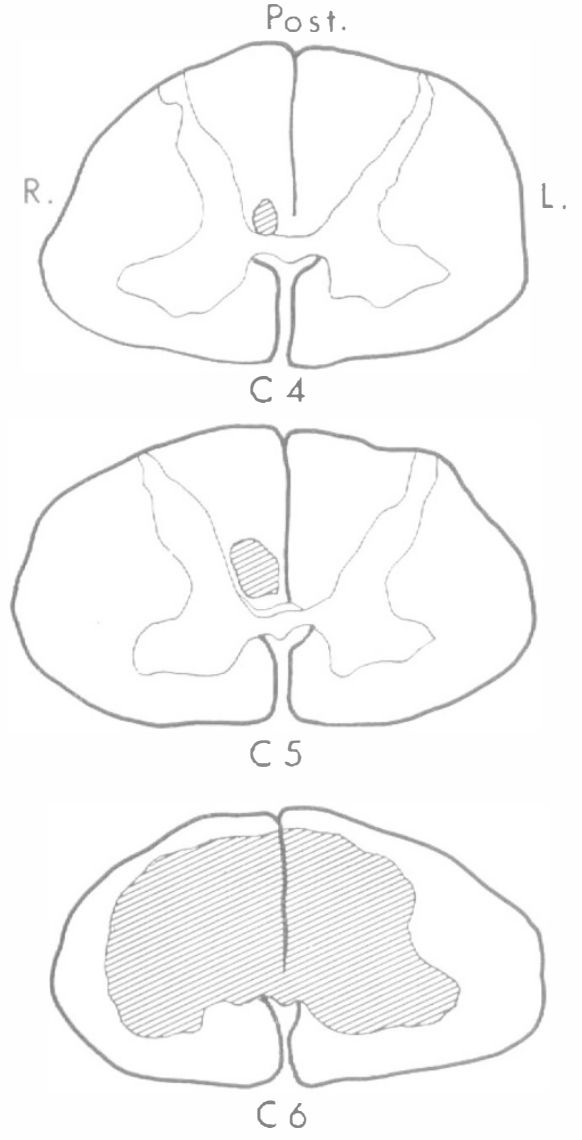

CASE 1 .

FIG 2

Diagrams from camera lucida tracings of histological sections through the spinal cord of Case I at $\mathrm{C}_{4}, \mathrm{C}_{5}$ and C6 segmental levels. The shaded area indicates the region of infarction.
Spinal Cord. The C5, 6 and 7 segments externally showed slight swelling. The anterior spinal artery at $\mathrm{C}_{5}, 6$ and 7 was bloodless, though normally filled above and below this level. On the posterior aspect the veins were empty over $\mathrm{C}_{5}, 6$ and 7 though very prominent below this down to the cauda equina.

Histological Examination of the Spinal Cord (fig. 2) $\mathrm{CI}_{1}, \mathrm{C}_{2}, \mathrm{C}_{3}, \mathrm{C}_{4}$ (upper). These segments showed moderate congestion and capillary proliferation. The neurones of the grey matter were depleted and those remaining were shrunken. These changes increased down the spinal cord and by the upper part of $\mathrm{C}_{4}$ had become on the verge of infarction.

$\mathrm{C}_{4}$ lower, $\mathrm{C}_{5}$ upper, $\mathrm{C}_{5}$ lower, C6 upper, C6 lower.) These segments contained a cone-shaped region of infarction first seen as a round area of necrosis ( $\mathrm{I} \mathrm{mm}$. in diameter) in the posterior columns immediately posterior to the grey commissure (fig. 3). In upper $\mathrm{C}_{5}$ this area enlarged and in lower $\mathrm{C}_{5}$ and both C6 sections (upper and lower) a large area of necrosis was present, involving most of the central part of the posterior columns and the grey matter. The grey matter was very hyperaemic and in $\mathrm{C} 6$ all neurones were destroyed.

(C7, C8, Ti, T2, T6, TIo, Li, sacral.) Only a trace of hyperaemia was present in $\mathrm{C}_{7}$ segment and below this the spinal cord was not remarkable.

Brain. This showed mild cerebral 


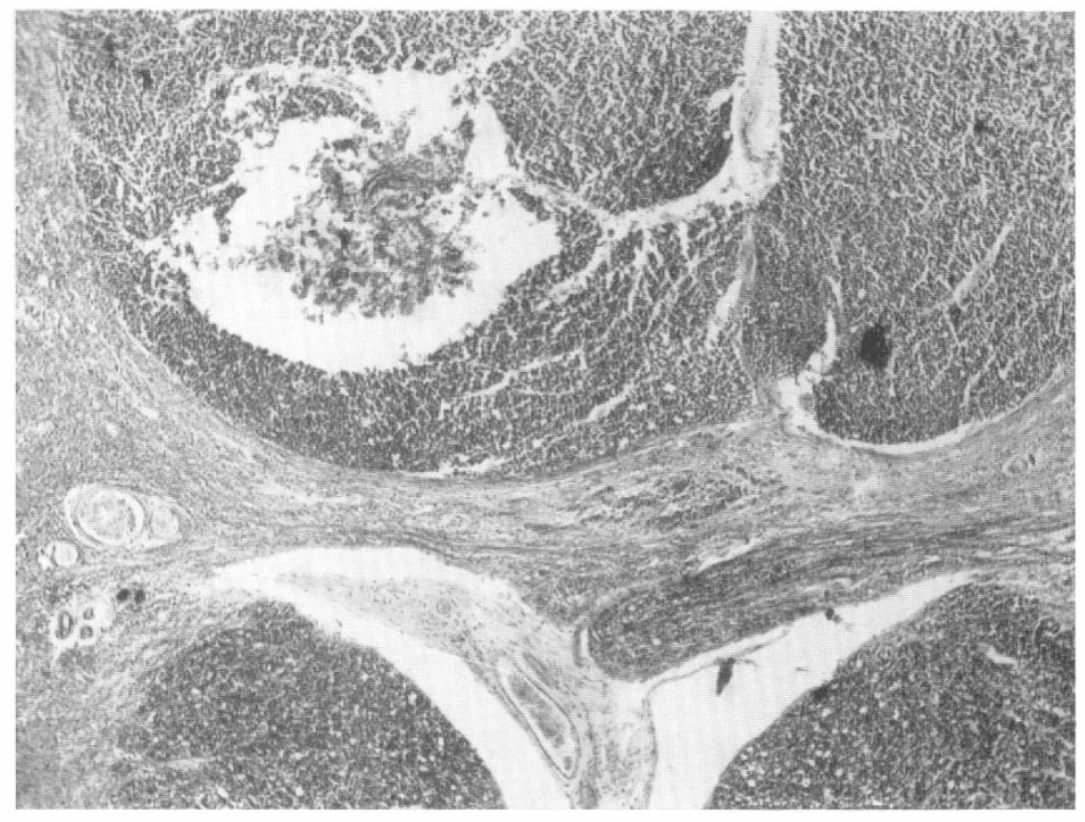

FIG 3

Case I. Photomicrograph of a histological section through the spinal cord at $\mathrm{C}_{4}$ segmental level showing the cephalic limit of the infarcted 'cone' as a round area of necrosis in the right posterior column. (Weil $\times 30$.)

swelling with a minor contusion to the left temporal lobe on its lateral aspect near the temporal pole. This contused area, $\mathrm{I} .5 \mathrm{~cm}$. in diameter, was the only evidence of trauma. The arteries comprising the circle of Willis were abnormal in that both posterior communicating arteries were large so that the blood flow to the posterior cerebral arteries was from the internal carotid arteries (fig. 4).

Summary of Case 1. A man of 52 sustained multiple injuries in a road accident. Although X-rays showed no fracture or displacement of the spine he developed a lower cervical cord syndrome. He died four days after his accident and at necropsy the spinal canal was normal but a tear through the C5-6 intervertebral disc had kinked both vertebral arteries. The spinal cord showed recent infarction of $\mathrm{C}_{4}, \mathrm{C}_{5}$ and $\mathrm{C} 6$ segments with ischaemic changes in other cervical cord segments.

Case 2. An 8I-year-old man fell downstairs, injuring his back. He went to bed but that night found his right side to be weak. His general practitioner was called, found a right hemiparesis without disturbance of consciousness or speech and arranged his admission to the Radcliffe Infirmary the following day. The examination on admission showed an obese man with a blood pressure of 190/100. He now had a tetraparesis but no sensory loss was found. A few hours later he had gross lower motor neurone paresis in the distribution of $\mathrm{C}_{6}$ and $\mathrm{C}_{7}$ and diminution of all sensation below C6. Both plantar reflexes were upgoing and he was incontinent of urine. An X-ray showed no fracture of the cervical spine but there was slight backward shift of C6 with 


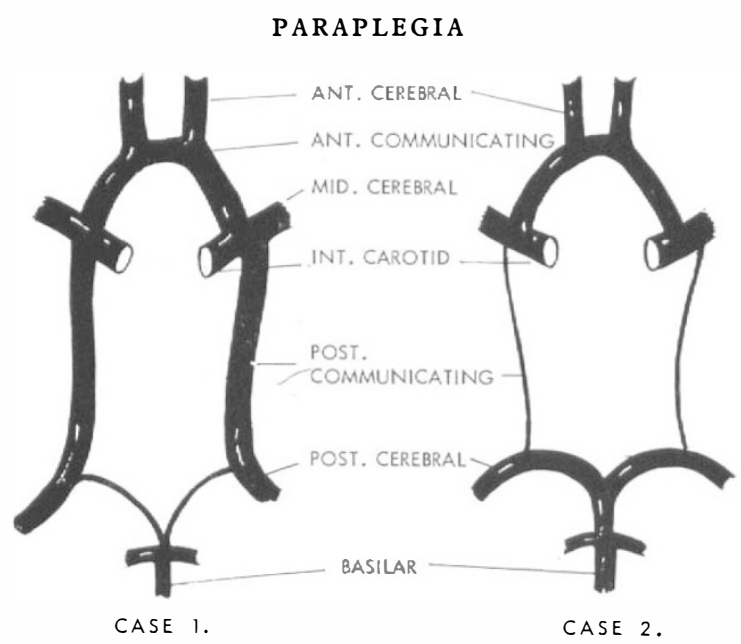

Fig 4

Diagrams representative of the circle of Willis in Case I and Case 2. Note the large posterior communicating arteries in Case I resulting in the posterior cerebral arteries being fed mainly from the internal carotids.

respect to $\mathrm{C}_{5}$ vertebra. He was put to bed with a sponge-rubber collar and during the next 24 hours there was no change in his neurological state. However, the following day, the third after his fall, his tetraplegia was more profound and his sensory level had certainly ascended now involving the $\mathrm{C}_{5}$ dermatome. A lumbar puncture showed slightly yellow fluid but there was no evidence of spinal block. Because of the progression of the cervical cord lesion a laminectomy was performed. The spinous processes and laminae of $\mathrm{C}_{3-7} 7$ were removed showing a thin film of extra-dural blood. On incising the dura the subarachnoid space was seen to be of normal size and when the arachnoid was opened the cord itself looked normal. It was in no way bruised or displaced and there was a copious flow of spinal fluid. Anteriorly there was no evidence of intervertebral disc protrusions nor of any other pressure on the cord. Immediately after his operation there was no significant neurological change but in the course of a month power returned to his lower limbs and to his upper limbs with the exception of the lower motor neurone weakness in the C8-TI distribution. Sensation recovered leaving patchy sensory loss below $\mathrm{C}_{7}$. $\mathrm{He}$ had several episodes of auricular fibrillation, attacks of bronchopneumonia and persistent urinary infection which led to his death in a geriatric hospital four months after his accident.

Necropsy. The general necropsy findings were acute bronchopneumonia, multiple pulmonary infarcts and cystitis with bilateral pyelonephritis.

Cervical Spine. The laminae of $\mathrm{C}_{3}-7$ vertebrae were absent, being replaced by a thick connective tissue scar of the previous laminectomy operation. Overlying the spinal cord at $\mathrm{C}_{4}-7$ was a $5-\mathrm{cm}$. sutured incision in the dura mater. The spinal cord was removed showing a normal spinal canal. The specimen was now cut sagittally (fig. 5), revealing a tear through C5-6 intervertebral disc, this dividing the spine into two portions which could be moved on one another but naturally lay in their normal anatomical relationships. No fracture was present, but the 


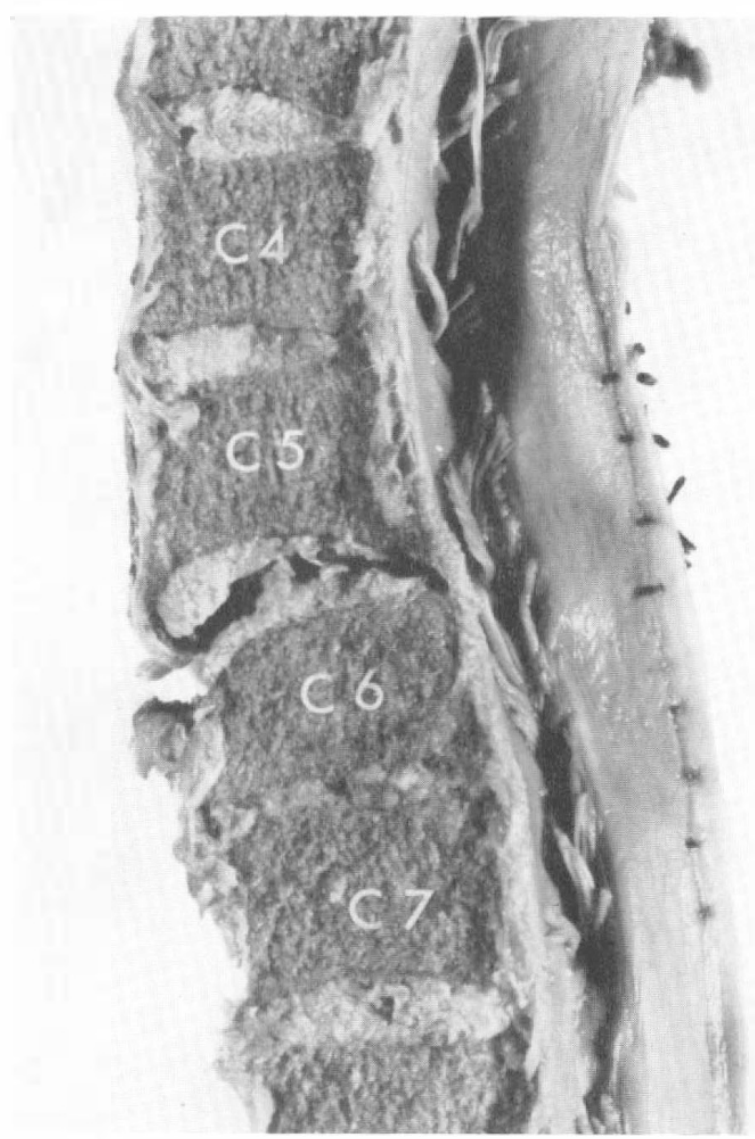

FIG. 5

Photograph of the cervical spine of Case 2. The specimen has been cut sagittally showing the tear through the C5-6 intervertebral disc.

intervertebral joints uniting C5-C6 were abnormally mobile with tearing of the capsular ligaments. The posterior longitudinal ligament was intact.

Vertebral Arteries. The course of the vertebral artery was investigated and on both sides there was kinking which could be made worse by extending the spine. Both vertebrals were injected with fluid whose passage could be stopped by extending the spine, the procedure and findings being identical with those in Case I.

Spinal Cord. The anterior spinal artery appeared normal and in the cervical region received major tributaries accompanying the right $\mathrm{C}_{4}$ and the left C6 anterior nerve roots (fig. I0). The spinal veins appeared normal. Transverse cuts across the spinal cord showed central yellowish discolouration of the lower cervical cord. 
Histological Examination of the Spinal Cord (figs. 6, 7, 8) (C2). The neurones and nerve roots were normal. Myelin and nerve fibre loss was marked in the gracile fasciculi, and in the anterior and posterior spino-cerebellar tracts. The appearances suggested Wallerian degeneration above a moderately complete cord lesion.

\section{FIGs. 6, 7, 8}

All these photomicrographs are from histological sections of the spinal cord of Case 2 at $\mathrm{C}_{7}$ segmental level.

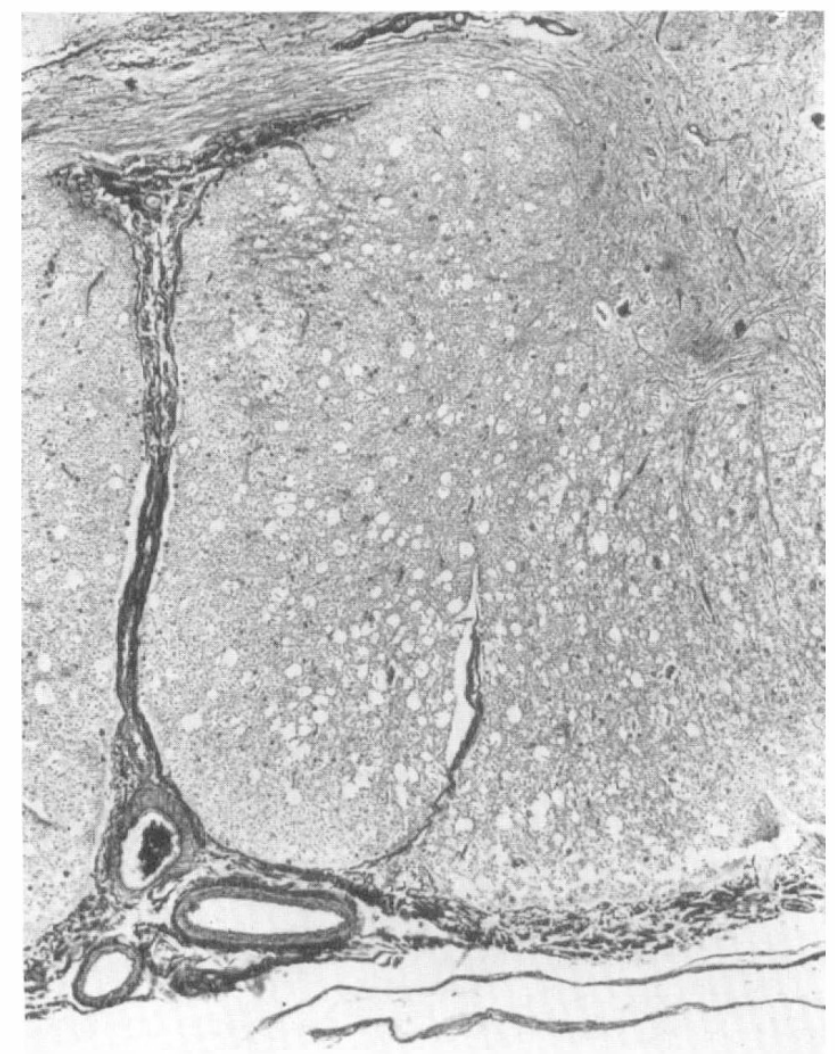

FIG. 6

Low-power view showing the anterior median sulcus, grey commissure, anterior horn and anterior white column. The white matter shows spongy myelin and fibre loss (worst centrally) whilst the grey matter of the anterior horn shows gliosis with depletion of neurones. (Holmes $\times 30$.)

$\left(\mathrm{C}_{3}, \mathrm{C}_{4}, \mathrm{C}_{5}\right.$.) In addition to the changes seen in $\mathrm{C}_{2}$, these segments showed capillary proliferation with fibrosis. A few shrunken neurones were present in the anterior horns among many normal neurone bodies.

$\left(\mathrm{C} 6, \mathrm{C}_{7}, \mathrm{C} 8, \mathrm{TI}\right.$.) These segments showed generalised myelin and fibre loss 


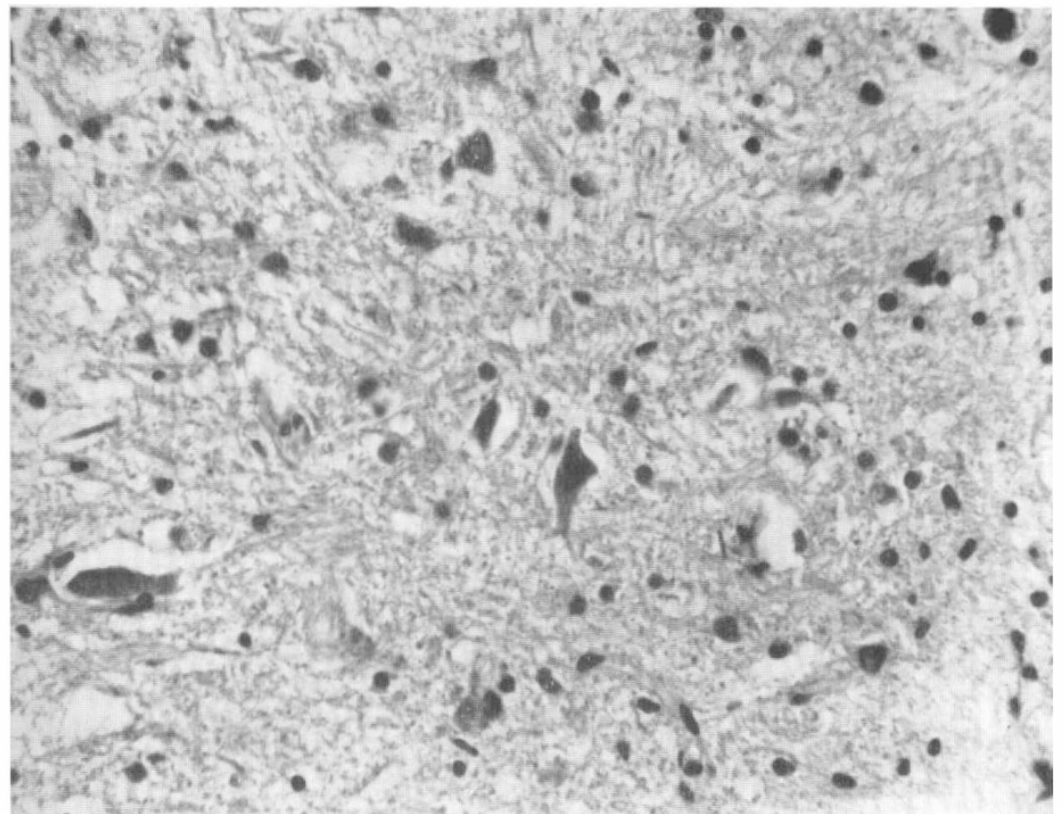

FIG. 7

High-power view of anterior horn showing gliosis and shrunken pyknotic neurones. (H. \& E. $\times 225$.)

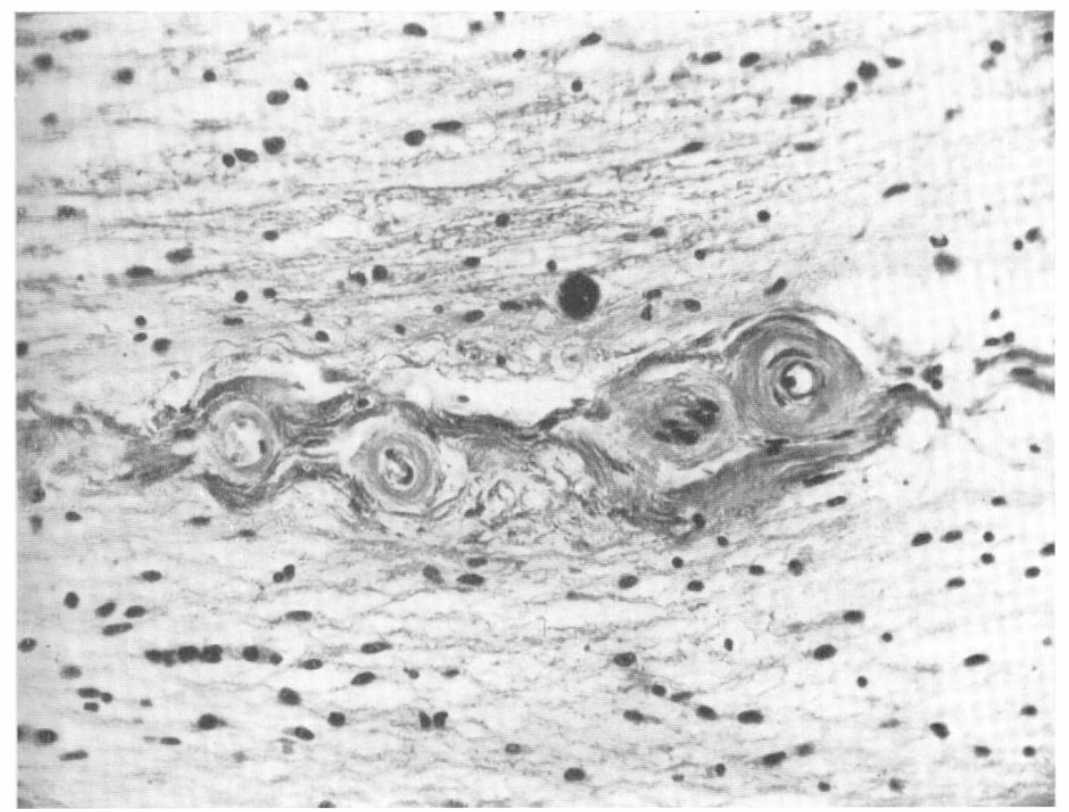

FIG. 8

High-power view of grey commissure showing small vessels surrounded by a condensation of fibrous tissue. (H. \& V. G. $\times 225$.) 
with astrocytic gliosis and prominent corpora amylacea. The anterior horns were slightly depleted of neurones but more striking was the presence of small shrunken pyknotic neurones. Capillary proliferation was marked with connective tissue hyaline thickening around the new vessels. These changes were also present in the anterior median sulcus and the leptomeninges.

(T2, T6, TI2, L2.) These segments showed only mild ischaemic changes but Wallerian degeneration was seen in the pyramidal tracts.

Brain. The circle of Willis appeared normal (fig. 4). On coronally slicing the fixed brain old infarction was seen on both sides posteriorly in the boundary territory between the middle and posterior cerebral arteries. Histological sections showed these areas to be replaced by a spongy gliosis with considerable loss of brain tissue (fig. 9).

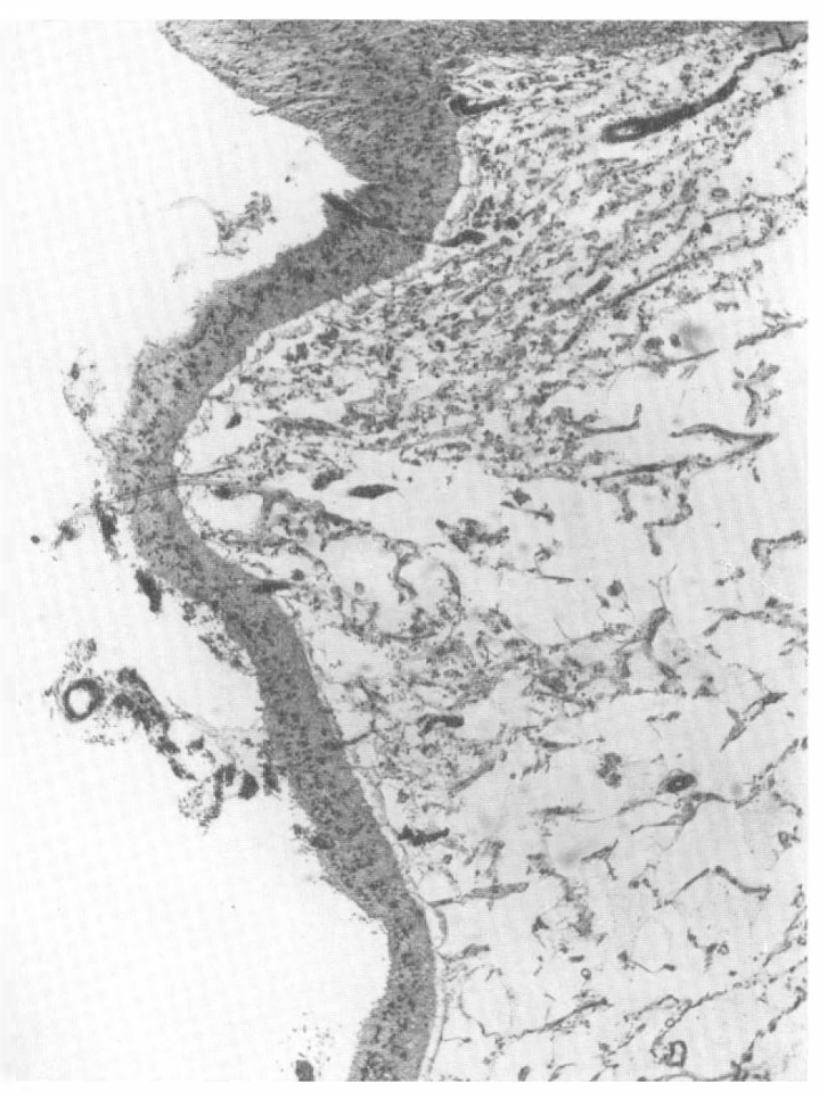

FIG. 9

Photomicrograph of cortical infarction in Case 2 seen in a coronal section of the caudal part of the left cerebral hemisphere. (H. \& E. $\times$ 40.)

Summary of Case 2. An 8I-year-old man fell downstairs injuring his spine and in the space of a few days developed a lower cervical cord syndrome. X-rays 
showed no fracture of the spine and at laminectomy the spinal canal was normal. Necropsy, four months later, showed tearing of the C5-6 intervertebral disc with kinking of both vertebral arteries. The spinal cord from $\mathrm{C}_{3}-\mathrm{T}_{\mathrm{I}}$ showed evidence of ischaemia also seen in the brain in the boundary zone between the posterior and middle cerebral artery territories.

Analysis of the Clinical and Pathological Findings. The clinical features of both these cases were in their essentials similar. Following an accident both patients developed, in the course of several hours, a lesion of the lower cervical spinal cord. X-rays of the cervical spine in both cases showed no fracture and the spinal canal seen at operation in Case 2 appeared normal. Death occurred after four days in Case I and after four months in Case 2, in the latter case some neurological improvement occurring in the first month.

The pathological finding common to both necropsies was a tear of the C5-6 intervertebral disc with abnormal angulation of the spine and kinking of both vertebral arteries. It could be demonstrated by fluid injection that in both cases the vertebral arteries were blocked when kinked by applying slight extension to the spine. The lower cervical spinal cord of both cases showed infarction recent in Case I, old in Case 2. Case 2 also showed old infarction in the boundary zone of the posterior cerebral and middle cerebral artery territories. This was not present in Case I, possibly due to an abnormal circle of Willis in that the posterior cerebral arteries were fed mainly from the internal carotid arteries.

\section{DISCUSSION}

The vertebral artery ascends in the vertebral foramina of the transverse processes of the upper six cervical vertebrae. In this part of its course it is vulnerable to atheromatous narrowing and occasionally involved by tumour, but these chronic and unilateral processes do not usually seriously impair the spinal cord blood supply. The main hazard is trauma for by this mechanism both vertebral arteries may be suddenly obstructed with serious consequences. The upper part of the spinal cord is dependent on the vertebral arteries not only for the intracranial branches forming the commencement of the single anterior and the two posterior spinal arteries but also for the reinforcement of these arteries by tributaries accompanying the anterior and posterior nerve roots (fig. Io). These tributaries come fron spinal branches arising from the vertebral arteries in their intravertebral course. From this it follows that obstruction to the proximal part of the vertebral artery has a dual effect. Not only are the tributaries to the anterior and posterior spinal arteries obstructed but the blood flow to the commencement of these three arteries is impaired. These features of the spinal cord blood supply make it difficult enough to predict the precise effect of an arterial obstruction, but there is yet another factor to consider. This is the major anastomosis between the internal carotid arteries and the vertebral-basilar system, this anastomosis comprising the circle of Willis. On this anastomosis, usually good but occasionally defective, depends whether the consequences of vertebral artery obstruction will be exerted on the brain (fig. 4). In Case I the posterior communicating arteries were unusually large, the posterior cerebral and basilar supply mainly came from the carotids and no ischaemic effects on the brain could be detected. In Case 2 the circle of Willis was of normal size and old infarction was present at the extreme limits of the vertebral-basilar supply in the 
caudal parts of the cerebral hemispheres. It remains to be considered how in these two cases the vertebral artery flow was impeded. Neither of the cases presented here had thrombosis of the vertebral arteries, but it could be demonstrated in the cadaver that extension of the neck obstructed the vertebral arteries and this sequel presum-

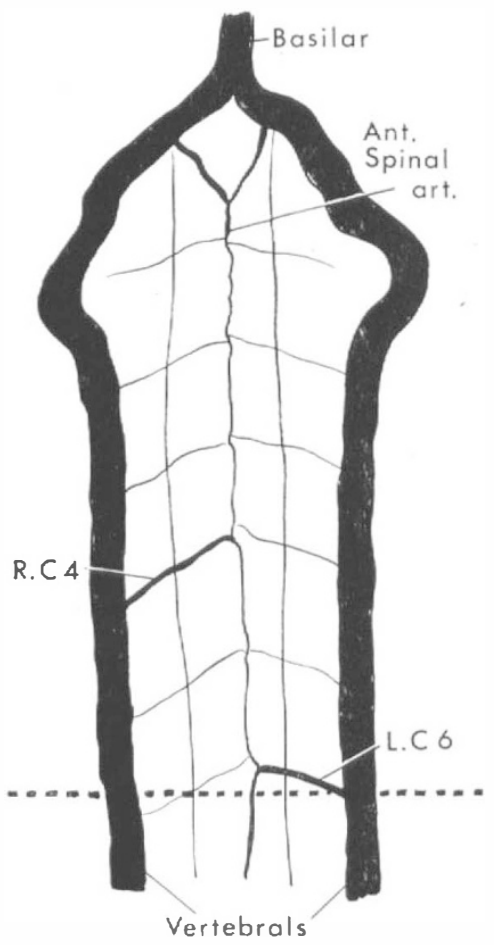

FIG. IO

Diagram showing the vertebral arteries and their tributaries to the anrerior spinal artery. The situation in Case $\mathbf{2}$ is illustrated where major tributaries accompanied the right $\mathrm{C}_{4}$ and the left C6 anterior nerve roots. The dotted line indicates the level of vertebral artery obstruction in both cases ably occurred during life. It is possible, however, that a contributory factor was arterial spasm provoked by the disc and capsular ligament tear, and such spasm was demonstrated by vertebral angiography in a case reported by Schneider and Schemm (I96I).

In the observed extent of the spinal cord infarction these two cases assist in understanding the complex blood supply of the spinal cord. In the cervical region with which we are here concerned the entire blood supply derives from the vertebral arteries which alone feed the single anterior and both posterior spinal arteries. From these three main spinal arteries, each in the longitudinal axis of the cord, arise coronal branches running circumferentially around the cord and penetrating branches (fig. II). In the case of the anterior spinal artery these penetrating branches are called sulcal arteries and pass backwards in the anterior median sulcus and turning left or right to enter the spinal cord. The penetrating branches from the posterior spinal arteries are smaller, the largest often entering accompanying the posterior nerve roots. These penetrating arteries, whether from anterior or posterior spinal arteries, supply the whole of the central part of the spinal cord save for a peripheral rim supplied by the coronal arteries. What the cases in this report show is that when the vertebral artery flow is seriously diminished the effect is mainly felt in the central region supplied by the penetrating arteries. For some reason, possibly the multiplicity of small branches, the peripheral rim supplied by the coronal branches is more resistant to a diminution of total blood flow. This central localisation of maximum infarction was seen in the necropsied case of Schneider, Thompson and Bebin (1958). It is recognised as a clincial syndrome in cervical spine injury and has been designated acute central necrosis of the spinal cord.

\section{CONCLUSIONS}

From the two cases detailed in this paper, the necropsied case of Schneider, Thompson and Bebin (1958) and the other similar but unconfirmed cases in the 


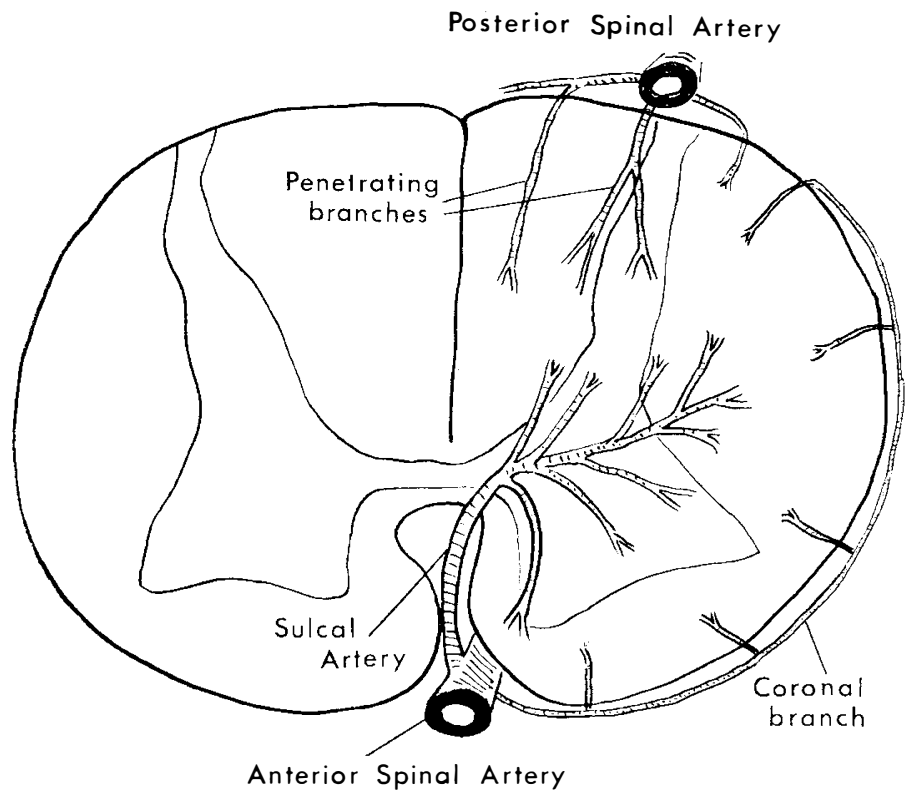

Fig. II

Diagram of the major arterial branches to a single cord segment. (After arterial injection studies.) Note the penetrating arteries supplying the centre of the spinal cord and the coronal branches supplying the peripheral rim of the cord.

literature, it is evident that vertebral artery obstruction may occur in cervical spine injury. The onset of clinical signs of a cervical cord lesion may be delayed for a period of hours or days and this delay may assist in diagnosis for in the cases where the spinal cord has been directly involved by trauma the neurological damage is immediately apparent. The neurological picture that develops corresponds to the pathological findings of a central region of ischaemia or infarction in the cervical region of the spinal cord.

Plain X-rays of the cervical spine may not reveal any abnormality, but the specialised technique of vertebral arteriography now available (Sheehan, Bauer and Meyer, I960) may confirm the vertebral artery obstruction. The treatment suggested by the mechanism of the vertebral artery obstruction is immobilisation of the cervical spine for by this simple measure the obstruction may be alleviated. Laminectomy is not indicated, although when performed in Case 2 there was no adverse effect observed. The prognosis for the patient is good if the acute phase of the quadriplegia is survived. Considerable improvement may be expected although much of the lower motor neurone damage in the upper limbs will be permanent.

\section{Summary}

Two cases are presented in which a lower cervical cord syndrome followed a cervical spine injury. The radiological examination during life showed no fracture or marked displacement but at necropsy tearing of the $\mathrm{C}_{5}-6$ disc was demonstrated 
in both cases. The vertebral arteries were kinked in their intravertebral course and this had caused spinal cord infarction. The central region of the spinal cord was principally involved giving the clinico-pathological syndrome of acute central necrosis of the spinal cord.

\section{RESUMÉ}

Deux cas avec un syndrôme d'atteinte de la moëlle cérvicale basse sont présentés. L'éxamen radiologique, au cours de la vie, ne montra aucune fracture ou déplacement, mais a l'autopsie, une déchirure du disque $\mathrm{C}_{5}-6$ a été démontrée. Les artères vertébrales furet recourbées sur elles-mêmes dans leurs trajets intra-vertébral causant un ramollissement de la moëlle épinière. La région centrale de la moëlle épinière fut principalement atteinte donnant un tableau clinico-pathologique d'atteinte myélomalacique aigüe de la moëlleépinière.

\section{ZUSAMMENFASSUNG}

In zwei Fällen verursachte Verletzung der Halswirbelsäule eine distale Läsion des Halsmarks.

Roentgenbilder zeigten weder Fraktur noch Luxation der Halswirbel. Bei der Obduktion wurde eine Zerreissung der Bandscheibe zwischen dem 5. und 6. Halswirbel gefunden. Die Aa. vertebrales zeigten Abknickung in ihrem intravertebralen Verlauf, was zu einem Infarkt im Mark geführt hatte. Das Zentrale Mark war am schwersten betroffen und zeigte das Syndrom einer akuten zentralwn Rückenmarksnekrose.

\section{REFERENCES}

BARNes, R. (1948). F. Bone ft Surg. 30B, 234.

BlackWOod, W. (1963). Personal Communication.

Hughes, J. T. \& BRownell, B. (1963). Lancet, I, 687.

SHEEHAN. S., BAUER, R. B. \& MeYer, J. S. (1960). Neurology (Minneap), ro, 968.

SChNeider, R. C., Cherry, G. \& Pantek, H. (1954). F. Neurosurg. II, 546.

SCHNEIDER, R. C. \& SCHEMM, G. W. (I96I). F. Neurosurg. 18, 348.

Schneider, R. C., Thompson, J. M. \& Bebin, J. (1958). F. Neurol. Neurosurg. Psychiat. 2I, 2 I 6.

SymoNDS, C. (1953). Larcet, I, 45I,

TAYLOR, A. R. \& Blackwood, W. (I948). F. Bone ft Surg. 30B, 245.

\section{ACKNOWLEDGEMENTS}

I should like to thank the clinical staff of the Radcliffe Infirmary, Oxford, for permission to report these two cases. Mr. Tugwell and Dr. Parry provided the photographs used, and I am indebted to Mrs. J. M. Smith for secretarial assistance. 